\title{
Effect of Hyaluronic Acid Gel on Healing of Simple Dental Extraction Sockets: A Pilot Study
}

\author{
Diana Mostafa*iD, Maram Alzahrani ${ }^{2} \mathbb{D}$, Jawharah Atiah Alatawi ${ }^{2}$, Samar Farhan Alsirhani ${ }^{2}$, Afrah Alshehri ${ }^{2} \mathbb{D}$, \\ Afnan Mazyed Almutiri ${ }^{2}$ \\ ${ }^{1}$ Department of Clinical Periodontology and Oral Medicine, Faculty of Dentistry, Alexandria University, Alexandria, Egypt; \\ ${ }^{2}$ Department of Preventive Dental Sciences, Vision Colleges, Riyadh, Saudi Arabia
}

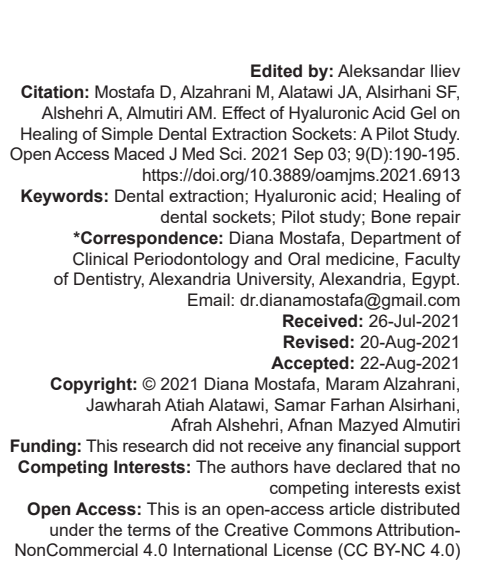

Abstract

BACKGROUND: Hyaluronic acid (HA) was explored as a powerful positive biocompatible material that participates in numerous biological processes related to morphogenesis and tissue healing

AIM: In this context, we elevated in this pilot study the effect of HA on soft tissue healing and bone repair of dental sockets (DS) as well as the postoperative pain.

MATERIALS AND METHODS: Ten individuals of both genders ( $80 \%$ females and $20 \%$ males) with age range 18-44 years, were included who were diagnosed with two non-restorable teeth (total sockets $n=20$ ). A split-mouth study design was performed where the DS of each patient were divided into Group A (study group): Topical oral HA gel (Gengigel ${ }^{\circledR}$ ) was applied into sockets while Group B (control group): Sockets were left untreated. Study variables were evaluated including socket length, socket healing scores (healing index), and post-operative pain in both groups at day 1,5 , and 10 for each patient.

RESULTS: There were no statistically significant differences between the control and study groups regarding the reduction of the socket length and postoperative complications but results revealed that HA enhances and fasten the healing capacity.

CONCLUSION: HA can be used as adjunctive treatment to improve the wound healing process.

\section{Introduction}

A dental extraction (DE) is one of the most common procedures in dental clinics. It is defined as the removal of teeth from the dental alveolus (socket) in the alveolar bone. It is performed most commonly for a badly prognosed or non-restorable tooth due to extensive caries, periodontal diseases, musculoskeletal diseases, and facial trauma [1].

The dental sockets (DS) in the healing process involve a series of orderly events including inflammation, overlapping phases of hemostasis, remodeling, and maturation [2]. DE may be followed by post-operative sequalae including pain and edema which may continue for several days after the extraction [3]. To minimize these complications and accelerate healing, various systemic medications, natural products, preservative materials, and irrigation procedures have been counted [4].

However, hyaluronic acid (HA) is known as sodium hyaluronate or hyaluronan. HA is one of the major components of the extracellular matrix which is widely distributed in several tissues involving the skin, synovial fluid, cartilage, tendons, eyes, and most body fluids [5]. Last decades, HA has been explored as a powerful biocompatible material for tissue engineering processes including morphogenesis and tissue healing [6].

It is found that HA has a significant role in the enhancementofwoundhealing byinducingearlygranulation tissue formation, hindering destructive inflammation, and endorsing re-epithelialization and angiogenesis. Furthermore, HA appears to have a positive effect on the reduction of post-operative swelling and inflammation [7]. In addition, it shows an imperative influence on bone repair by stimulating the cell migration, adhesion, and proliferation of undifferentiated mesenchymal cells into osteoblastic cells [7], [8]. Furthermore, it has the ability to retain osteoinductive growth factors in local environment, mediating the adhesion of osteoclasts to the bone surface leading to bone formation [9].

Even though HA has been extensively used as an alternative treatment for many conditions in many medical fields, HA applications in dentistry are still not well explored. In this context, this study was done to evaluate the clinical impact of HA on extracted sockets regarding bone repair, tissue healing, and postoperative complications. 


\section{Materials and Methods}

\section{Recruitment of subjects}

Our prospective study was conducted from January 2021 to June 2021 on 15 patients of both genders who were diagnosed with two non-restorable teeth (indicated for extraction) and in Vision dental hospital, Riyadh, KSA (Figure 1). Patients enrolled in this study were selected randomly according to inclusion and exclusion criteria as follows:

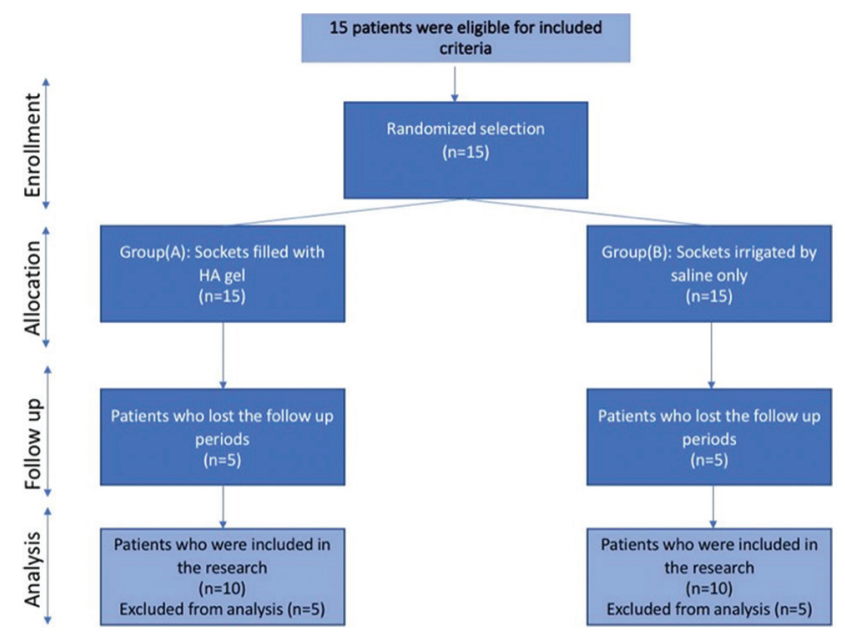

Figure 1: Study flow diagram

\section{Inclusion criteria}

study:

The following criteria were included in the

1. Healthy patients without any systemic disease

2. Age above 18 years old

3. Participants had at least 2 non-resorbable single-rooted teeth indicated for simple extraction

4. No oral pathological lesions related to the selected teeth.

\section{Exclusion criteria}

The following criteria were excluded from the study:

1. Patients with systemic diseases or a history of allergy to $\mathrm{HA}$ or cosmetic fillers containing $\mathrm{HA}$

2. Tobacco use

3. Patients needed surgical extraction

4. Any patients under antibiotic therapy in the last 3 months, oral contraceptives, immunosuppressive drugs, radiotherapy and chemotherapy

5. Pregnant or lactating mother

6. Mentally disturbed patients.

\section{Study design}

The pilot study with split-mouth design was performed in which the DS of each patient were divided into two groups; Group A (study group) received topical oral HA gel (Gengige ${ }^{\circledR}$ ) which was inserted into post-extracted sockets while Group B (control group) represented the untreated DS.

\section{Clinical procedures}

The study protocol was approved by the institutional review board of Vision colleges, Riyadh, KSA (protocol \# alf-dent-2020059). Each participant received detailed information and provided a signed written consent regarding the research.

For the clinical examination, a single-blinded examiner used clinical examination instruments, along with digital periapical radiographs to establish the diagnosis. This was done after documenting patient data (age and gender), medical, and dental histories. Pre-operative variables (sign and symptoms related to the indicated teeth) and type of extracted tooth were also collected.

After local anesthesia administration ( $2 \%$ lidocaine with $1: 100,000$ epinephrine), extraction of teeth of both groups was done at the same time on the dental chair using the aseptic minimal traumatic technique. Immediately after extraction, the DS were divided into group A (study group) where topical oral HA gel $\left(\right.$ Gengigel $^{\circledR}$ ) was inserted using cotton pellet into the socket (Figure 2), then the patient was instructed to place this gel 3 times a day without any washing activities after application, while Group B (control group) represented the other half of indicated sockets, that left untreated to be naturally filled with blood clot.

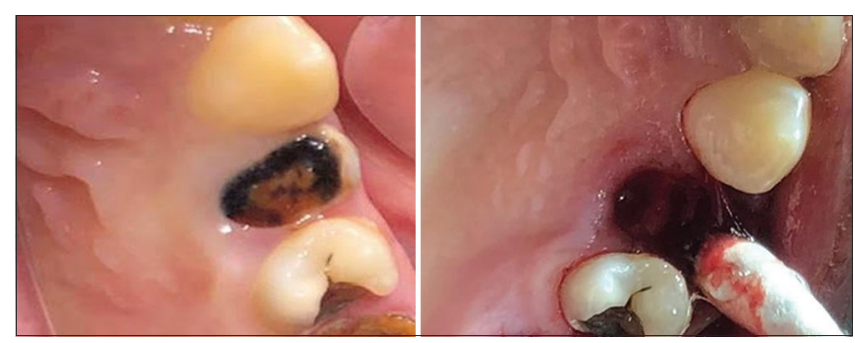

Figure 2: Application of hyaluronic acid gel after extraction of nonrestorable teeth

\section{Clinical comparative variables}

Study variables were evaluated preoperatively and postoperatively including socket length, socket healing scores (healing index) and post-operative pain to evaluate the healing of the bone and soft tissues in both groups on days 1, 5, and 10 for each patient. 


\section{Bone healing}

To determine the results of bone repair, digital periapical radiographs were taken before, immediately and after 5 and 10 days of extraction and bone repair capacity of healing sockets of both groups were evaluated regarding socket lengths. Where, the length of the socket was measured from the crest of bone to the alveolar fundus in each radiographic picture. We established an equation that gave bone repair percentage to assess the improvement of bone healing after 10 days. The equation was

(Original socket length ${ }_{1}-$ Present socket length 2 ) $\times 100$

$$
\text { Original socket length }
$$

The overall responses were categorized compared with the baseline responses as follows;

$\begin{array}{ll}\text { - } & \text { No improvement - } 0 \% \\ \text { - } & \text { Poor improvement }-<25 \% \\ \text { - } & \text { Gair improvement - } 25-50 \% \\ \text { - } & \text { Excellent improvement }->75 \% .\end{array}$

\section{Wound healing index (WHI)}

It was calibrated to document the gingival inflammation signs; tissue color, bleeding response on palpation, incision margin closure, and suppuration formation of the healing socket using the healing index done by Landry et al. [10]. Each socket was given a score from 1 (very poor healing) to 5 (excellent healing).

Score 1 (very poor healing): $\geq 50 \%$ of red gingiva, bleeding on tissue palpation, presence of granulation tissues, not epithelialized margins with loss of epithelium beyond margins, and presence of suppuration.

Score 2 (poor healing): $\geq 50 \%$ of red gingiva, bleeding on tissue palpation, presence of granulation tissues, not epithelialized margins with exposed connective tissue, and absence of suppuration.

Score 3 (good healing): $25-50 \%$ of red gingiva, no bleeding on tissue palpation, no granulation tissues, no exposed connective tissue, and no suppuration.

Score 4 (very good healing): $<25 \%$ of red gingiva, no bleeding on tissue palpation, no granulation tissues, no exposed connective tissue, and no suppuration.

Score 5 (excellent healing): No red gingiva, no bleeding on tissue palpation, no granulation tissues, no exposed connective tissue, and no suppuration.

\section{Post-operative complications}

A subjective evaluation of post-operative pain was established using the visual analog scale (VAS) where patients were asked to grade the severity of their post-operative pain in numbers from 1 (very mild pain) to 10 (very severe pain) at days 1,5 , and 10 . A question was asked each follow-up visit "How much pain do you have today?" In addition, the presence of suppuration evaluation was scored (no suppuration $=0$ and presence of suppuration $=1$ ). In addition, clinical photographs were taken before DE, immediately after extraction and during follow-up periods to document the healing scores of the tissues.

\section{Statistical analysis}

Data were coded for entry and analysis using SPSS statistical software package version 23. Data were presented using descriptive statistics in the form of frequencies and percentages. Interval and ratio variables were presented in the form of means and standard deviations. An independent t-test was used to compare the interval and ratio between groups. The significance level was chosen as $p<0.05$.

\section{Results}

Fifteen patients ( 6 males and 9 females with 30 DEs) were included in our study following the study criteria, but only ten patients ( 2 males and 8 females) with ages ranged 18-44 years who established all follow-up periods (Figure 1). The gender and age variables were analyzed by calculating the frequency and percentage of participants as shown in Table 1. On comparing the two studied groups regarding gender, it was found that there was no significant difference between the two studied groups $(p>$ $0.05)$. In addition, there was no significant difference between the two studied groups regarding age ( $p>$ 0.05).

Table 1: Frequency distribution of gender and age data sample

\begin{tabular}{lll}
\hline Characterization of patients & Frequency & Percent \\
\hline Gender & 2 & \\
Male & 2 & 20.0 \\
Female & 8 & \\
Age & 4 & 40.0 \\
$20-29$ & 4 & 40.0 \\
$30-39$ & 2 & 20.0 \\
$40-49$ & 2 & \\
\hline
\end{tabular}

Twenty DS were enrolled in this study, Group A had five mandibular premolars, three maxillary premolars and two mandibular anterior post-extracted sockets, while Group B included six mandibular premolars, three maxillary premolars, and one mandibular anterior postextracted sockets.

Table 2 and Figure 3 exhibit the difference in the socket lengths between both groups (control and study group) at different periods of follow-up. It is clear that the levels of significance for each socket length in different visits were $(0.760,0.509,0.657$, and 0.872$)$, respectively immediately, at days 5 and 10 . The results were more 
than (0.05) exploring no difference between the socket length between both groups in all follow-up periods.

Table 2: Comparison of the socket lengths between control and study groups during the follow-up periods

\begin{tabular}{|c|c|c|c|c|}
\hline \multirow[t]{2}{*}{ Variable } & \multirow{2}{*}{$\begin{array}{l}\text { Control } \\
\text { mean }\end{array}$} & \multirow{2}{*}{$\begin{array}{l}\text { Study } \\
\text { SD }\end{array}$} & \multirow[t]{2}{*}{ t-test } & \multirow[t]{2}{*}{$\mathrm{p}$-value } \\
\hline & & & & \\
\hline \multicolumn{5}{|c|}{ Socket length in visit 1} \\
\hline Study group & 8.458 & 3.217 & \multirow[t]{2}{*}{0.096} & \multirow[t]{2}{*}{0.760} \\
\hline Control group & 10.972 & 3.248 & & \\
\hline \multicolumn{5}{|c|}{ Socket length in visit 2} \\
\hline Study group & 7.480 & 2.893 & \multirow[t]{2}{*}{0.455} & \multirow[t]{2}{*}{0.509} \\
\hline Control group & 9.170 & 3.318 & & \\
\hline \multicolumn{5}{|c|}{ Socket length in visit 3} \\
\hline Study group & 6.889 & 3.973 & \multirow[t]{2}{*}{0.203} & \multirow[t]{2}{*}{0.657} \\
\hline Control group & 8.685 & 3.758 & & \\
\hline \multicolumn{5}{|c|}{ Socket length Total visit } \\
\hline Study group & 0.258 & 0.328 & \multirow[t]{2}{*}{0.027} & \multirow[t]{2}{*}{0.872} \\
\hline Control group & 0.320 & 0.379 & & \\
\hline
\end{tabular}

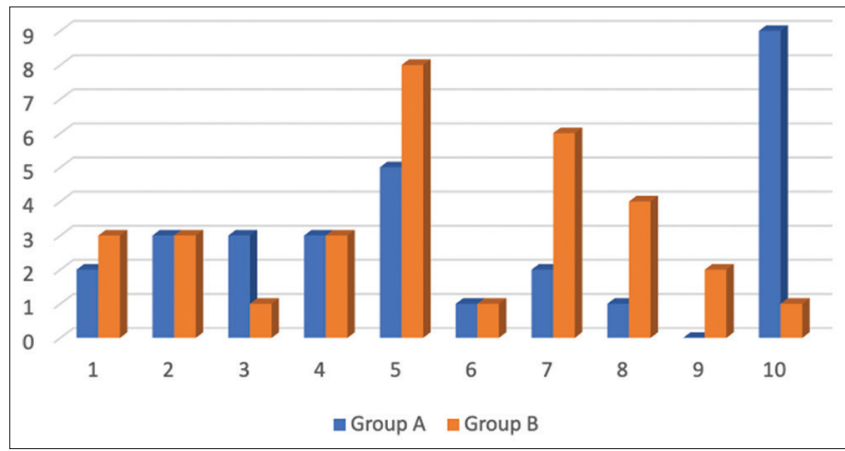

Figure 3: Comparison between both groups regarding socket length

Table 3 and Figure 4 demonstrate the responses of both groups regarding improvement percentage of bone healing after 10 days of extraction.

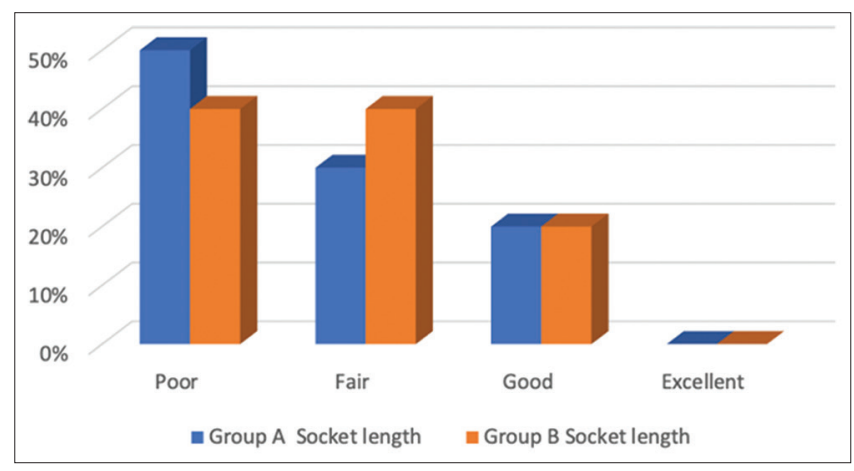

Figure 4: Improvements of the bone healing in both groups after 10 days

Regarding the socket length reduction, none of both groups exhibited complete healing of the DS. In Group A (study group) $20 \%$ revealed a good response to the treatment, $30 \%$ of the DS showed a decrease in socket length while $50 \%$ of the sockets presented poor improvement of bone healing.

Table 3: The socket length improvements of both groups after 10 days

\begin{tabular}{|c|c|c|}
\hline \multirow[t]{2}{*}{ Improvements } & Study group (Group A) (\%) & Control group (Group B) (\%) \\
\hline & Socket length & Socket length \\
\hline No improvement & $0(0)$ & $0(0)$ \\
\hline Poor & $5(50)$ & $4(40)$ \\
\hline Fair & $3(30)$ & $4(40)$ \\
\hline Good & $2(20)$ & $2(20)$ \\
\hline Excellent & $0(0)$ & $0(0)$ \\
\hline
\end{tabular}

On the other hand, Group B (control group) revealed 20\%, $40 \%$, and $40 \%$ of good, fair, and poor improvements in bone healing correspondingly.
Table 4 and Figure 5 display the compassion between both groups regarding WHI after 10 days. Results revealed there was a significant difference between both groups regarding healing index as $p<0.05$. In Group A (study group), $50 \%$ of the sockets showed excellent healing, $10 \%, 30 \%$, and $10 \%$ of sockets revealed good, fair, and poor improvement, respectively.

Table 4: Compassion between both groups regarding WHI after 10 days

\begin{tabular}{llll}
\hline Wound healing index & Study group (Group A) & Control group (Group B) & p-value \\
\hline Very poor healing & $0(0)$ & $0(0)$ & $<0.001^{*}$ \\
Poor healing & $1(10)$ & $1(10)$ & \\
Fair healing & $3(30)$ & $4(40)$ & \\
Good healing & $1(10)$ & $3(30)$ & \\
Excellent healing & $5(50)$ & $2(20)$ & \\
\hline${ }^{*}$ Statistically significant at $\mathrm{p} \leq 0.05$. & &
\end{tabular}

In Group B (control group), 20\% only of the DS showed excellent healing of soft tissues, $30 \%$ of the sockets displayed a reduction of the scores and $40 \%$ of sockets showed fair improvement while $10 \%$ showed poor healing of soft tissues. Regarding the postoperative pain, neither group A nor Group B had any postoperative complications including pain and suppuration, where no statistics could be done.

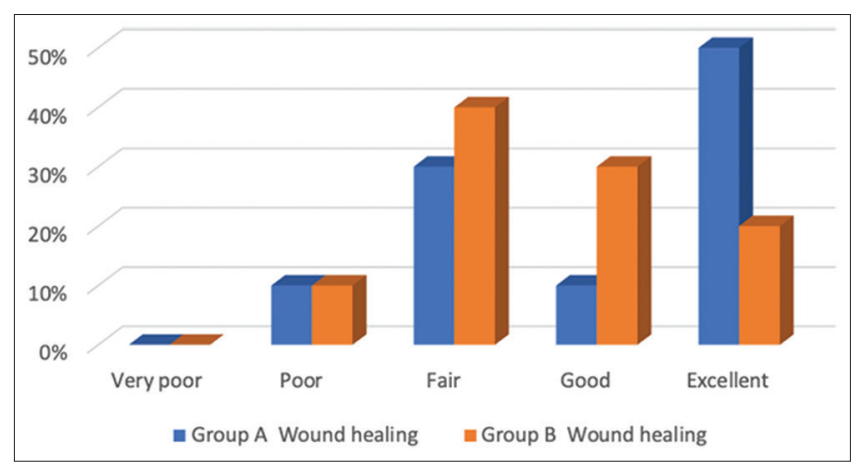

Figure 5: Wound healing index of both groups after 10 days

\section{Discussion}

HA is an important element in the soft periodontal tissues, gingiva, and periodontal ligament, and in the hard tissue, such as alveolar bone and cementum [11]. The present study was conducted to evaluate the efficacy of HA on the healing and repair of hard and soft tissue with the control of post-operative pain following closed tooth extraction. We compared extracted sockets with topical HA of the same patients in comparison to non-intervention post-extracted sockets to minimalize the individual factors that might intrude on the study results.

We started our research with 15 patients (30 sockets) who fulfilled the research criteria but only ten patients who accomplished the study. Five patients did not complete the follow-up visits, the explanation of the small sample size and incompliance of follow-up visits is the fear of COVID 19 infection as well as going to the dental hospitals for no emergency reasons. However, 10 patients were enrolled (20 sockets) as two males 
and eight females were included following the study criteria with ages ranged 18-44 years. The results showed that there was no difference between both genders regarding the socket length, healing scores, and post-operative pain. There were more female cases than male cases, possibly due to hormonal disturbance during puberty, menses, and pregnancy impacting the calcitonin levels, leading to damaging soft and hard oral tissues, along with carelessness toward regular dental appointments resulting in non-restorable teeth.

In our study, single-rooted teeth were involved such as anterior teeth and premolars to facilitate the standardization of measuring the root lengths. We assessed the bone healing by measuring the socket length using the digital preapical radiograph on each day 1 , day 5 , and day 10 . Our results showed no significant difference between both groups regarding the reduction of socket length.

These results were in agreement with de britro Bezerra et al. [12] who made a study in 2011 on animals and showed that HA $1 \%$ gel alone did not show any significant results in bone formation except when using it with collagen sponge in bone defects, in addition, Aslan et al. [13] in 2006 concluded that HA needs a scaffold to improve the rate of bone formation in rabbits.

While our results were not in agreement with another experimental study done by Suzuki et al. [14] which revealed that HA promoted bone formation when it was applied to bone defects in animal models. Furthermore, Mendes et al. [2] found that there was a significant increase in the early healing period in bone trabeculae at 7 days after tooth extraction as the expression of BMP-2 and osteopontin was enhanced in HA treated sockets of rats. Furthermore, Yilmaz, et al. [15] supported that HA promoted bone healing after surgical wisdom tooth extraction. On the other hand, Alcântara et al. [16] stated that there was high bone formation rate in lower first premolar human sockets filled with $\mathrm{HA}$ at 30 days but there was no difference between HA and control groups after 90 days even in the alveolar bone dimensions.

Regarding the soft tissue healing, our outcomes revealed that there was a statistical difference in healing index between the sockets treated with HA gel and the non-intervention sockets, where $50 \%$ of study sockets (Group A) exhibited excellent healing after 10 days while $20 \%$ of sockets of Group B displayed excellent healing. This is because of the ability of HA in promoting the inflammatory cytokines such as IL-1 $\beta$ and $\mathrm{TNF}-\alpha$, triggering angiogenesis and activating keratinocytes and fibroblasts during the healing process [17]. Our outcomes were in accordance with many studies [2], [16], [18] which concluded that HA enhances and fastens the repair time. Our findings were not corresponding to Mostafa et al. [19] and Aebli et al. [20] who stated that HA does not have any significant effect on healing time or repair capacity.
In our study, measuring post-operative pain was recorded by using VAS in the immediate postoperative, days 5 and 10. Brokelman et al. [21] stated that the VAS scale is used to evaluate the postsurgical pain and satisfaction of a patient with the intraclass coefficient of 0.95. Our findings concluded that there were no postoperative complications including pain and suppuration in both groups, this is maybe because the selected cases were simple extraction (no indication of surgical flaps) without any signs of preoperative pathological infection. This study showed similar results to Bayoumi et al. [22] who concluded that HA did not decrease either the incidence of dry socket formation or postoperative pain and also Koray et al. [23] who found that there were no statistically significant differences in VAS scores between the different treatments modalities including HA spray on the $1^{\text {st }}, 2^{\text {nd }}$, and 7 days after surgical extraction of impacted mandibular third molar.

Although our sample was small, our study was split-mouth design to ensure the same conditions on both groups during comparison. However, since the study samples only represented the findings of selected groups of patients, it would be beneficial to re-evaluate the effect of HA on a larger sample with a longer follow-up period and histological investigations.

\section{Conclusion}

The results of this study allow the conclusion that HA administration showed no significant effect on bone healing of the extracted sockets but it enhances and fastens the soft tissue healing capacity. However, $\mathrm{HA}$ could be an effective adjunctive treatment for improving the wound healing process.

\section{References}

1. Bodic F, Hamel L, Lerouxel E, Baslé MF, Chappard D. Bone loss and teeth. Joint Bone Spine. 2005;72(3):215-21. https://doi. org/10.1016/j.jbspin.2004.03.007

PMid:15850992

2. Mendes RM, Silva GA, Lima MF, Calliari MV, AlmeidaAP, Alves JB, et al. Sodium hyaluronate accelerates the healing process in tooth sockets of rats. Arch Oral Biol. 2008;53(12):1155-62. https://doi.org/10.1016/j.archoralbio.2008.07.001 PMid:18692778

3. Preetha S. An overview of dry socket and its management. IOSR J Dent Med Sci. 2014;13(5):32-5

4. Sharif MO, Dawoud BE, Tsichlaki A, Yates JM. Interventions for the prevention of dry socket: An evidence-based update. Br Dent J. 2014;217(1):27-30. https://doi.org/10.1038/sj.bdj.2014.550 PMid:25012325 
5. Prince $\mathrm{CW}$. Roles of hyaluronan in bone resorption. BMC Musculoskelet Disord. 2004;5(1):12.

\section{PMid:15117412}

6. Chen F, Ni Y, Liu B, Zhou T, Yu C, Su Y, et al. Self-crosslinking and injectable hyaluronic acid/RGD-functionalized pectin hydrogel for cartilage tissue engineering. Carbohydr Polym. 2017;166:31-44. https://doi.org/10.1016/j.carbpol.2017.02.059 PMid:28385238

7. Kim J, Kim IS, Cho TH, Lee KB, Hwang SJ, Tae G, et al. Bone regeneration using hyaluronic acid-based hydrogel with bone morphogenic protein-2 and human mesenchymal stem cells. Biomaterials. 2007;28(10):1830-7. https://doi.org/10.1016/j. biomaterials.2006.11.050

PMid:17208295

8. Pasquinelli G, Orrico C, Foroni L, Bonafè F, Carboni M, Guarnieri C, et al. Mesenchymal stem cell interaction with a non-woven hyaluronan-based scaffold suitable for tissue repair. J Anat. 2008;213(5):520-30. https://doi. org/10.1111/j.1469-7580.2008.00974.x

PMid:19014359

9. Giavaresi G, Torricelli P, Fornasari PM, Giardino R, Barbucci R, Leone $\mathrm{G}$. Blood vessel formation after soft-tissue implantation of hyaluronan-based hydrogel supplemented with copper ions. Biomaterials. 2005;26(16):3001-8. https://doi.org/10.1016/j. biomaterials.2004.08.027

PMid:15603795

10. Landry RG, Turnbull RS, Howley T. Effectiveness of benzydamyne $\mathrm{HCl}$ in the treatment of periodontal post-surgical patients. Res Clin Forums. 1988;10:105-18.

11. Dahiya P, Kamal R. Hyaluronic acid: A boon in periodontal therapy. N Am J Med Sci. 2013;5(5):309-15.

PMid:23814761

12. de Brito Bezerra B, Brazão MA, de Campos ML, Casati MZ, Sallum EA, Sallum AW. Association of hyaluronic acid with a collagen scaffold may improve bone healing in critical-size bone defects. Clin Oral Implants Res. 2012;23(8):938-42. https://doi. org/10.1111/j.1600-0501.2011.02234.x

PMid:21689163

13. Aslan M, Simsek G, Dayi E. The effect of hyaluronic acidsupplemented bone graft in bone healing: Experimental study in rabbits. J Biomater Appl. 2006;20(3):209-20. https://doi. org/10.1177/0885328206051047 PMid:16364962

14. Suzuki $\mathrm{K}$, Anada $\mathrm{T}$, Miyazaki $\mathrm{T}$, Miyatake $\mathrm{N}$, Honda $\mathrm{Y}$, Kishimoto KN, et al. Effect of addition of hyaluronic acids on the osteoconductivity and biodegradability of synthetic octacalcium phosphate. Acta Biomater. 2014;10(1):531-43. https://doi. org/10.1016/j.actbio.2013.09.005

\section{PMid:24035888}

15. Yilmaz N, Demirtas N, Kazancioglu HO, Bayer S, Acar AH Mihmanli A. The efficacy of hyaluronic acid in postextraction sockets of impacted third molars: A pilot study. Niger J Clin Pract. 2017;20(12):1626-31

PMid:29378998

16. Alcântara CE, Castro MA, Noronha MS, Martins-Junior PA, Mendes RM, Caliari MV, et al. Hyaluronic acid accelerates bone repair in human dental sockets: A randomized triple-blind clinical trial. Braz Oral Res. 2018;32:e84. https://doi.org/10.1590/18073107bor-2018.vol32.0084 PMid:30231173

17. Kawano Y, Patrulea V, Sublet E, Borchard G, lyoda T, Kageyama $\mathrm{R}$, et al. Wound healing promotion by hyaluronic acid: Effect of molecular weight on gene expression and in vivo wound closure. Pharmaceuticals (Basel). 2021;14(4):301. https://doi.org/10.3390/ph14040301 PMid:33800588

18. Yazan M, Kocyigit ID, Atil F, Tekin U, Gonen ZB, Onder ME. Effect of hyaluronic acid on the osseointegration of dental implants. Br J Oral Maxillofac Surg. 2019;57(1):53-7. https://doi. org/10.1016/j.bjoms.2018.08.014

PMid:30558816

19. Mostafa M, Shamma BD, Ayad SS, El-Dibany RM, Nagui DA Evaluation of the effect of hyaluronic acid mixed with biphasic calcium phosphate on bone healing around dental implants (experimental study). Alex Dent J. 2017;42(1):104-11. https:// doi.org/10.21608/adjalexu.2017.57868

20. Aebli N, Stich H, Schawalder P, Theis JC, Krebs J. Effects of bone morphogenetic protein-2 and hyaluronic acid on the osseointegration of hydroxyapatite-coated implants: An experimental study in sheep. J Biomed Mater Res A. 2005;73(3):295-302. https://doi.org/10.1002/jbm.a.30299 PMid:15834931

21. Brokelman RB, Haverkamp D, van Loon C. The validation of the visual analogue scale for patient satisfaction after total hip arthroplasty. Eur Orthop Traumatol. 2012;3(2):101-5. https://doi. org/10.1007/s12570-012-0100-3 PMid:22798966

22. Bayoumi AM, Jan A, Amoudi WA, Shakir M. The effects of using hyaluronic acid on the extraction sockets. Int J Dent Oral Health. 2015;2(1):1-5.

23. Koray $M$, Ofluoglu D, Onal EA, Ozgul M, Ersev $H$, Yaltirik $M$, et al. Efficacy of hyaluronic acid spray on swelling, pain, and trismus after surgical extraction of impacted mandibular third molars. Int J Oral Maxillofac Surg. 2014;43(11):1399-403. https://doi.org/10.1016/j.ijom.2014.05.003

PMid:24924267 